\title{
BIOSYNTHESIS AND CHARACTERIZATION OF SILVER NANOPARTICLES USING KING OYSTER (PLEUROTUS ERYNGII) EXTRACT: EFFECT ON SOME MICROORGANISMS
}

\author{
ACAY, H. ${ }^{1 *}-$ BARAN, M. F. ${ }^{2}$ \\ ${ }^{I}$ Department of Nutrition and Dietetic, School of Health, Mardin Artuklu University, Mardin, \\ Turkey \\ ${ }^{2}$ Medical Laboratory Techniques, Vocational Higher School of Healthcare Studies, Mardin \\ Artuklu University, 47200 Mardin, Turkey \\ *Corresponding author \\ e-mail: hilalacay@gmail.com
}

(Received 21 ${ }^{\text {st }}$ Mar 2019; accepted 24 ${ }^{\text {th }}$ May 2019)

\begin{abstract}
The integration of the principles of green chemistry into nanotechnology has become one of the key issues in nanotechnology research. Metal nanoparticle production, which does not contain toxic chemicals and does not harm the environment, needs to be developed to avoid adverse effects on medical applications. In this study, Pleurotus eryngii (PE) extract was used for preparation of silver nanoparticles (AgNPs). The presence of AgNP was understood that after adding $1 \mathrm{mM}$ silver nitrate (AgNO3) to the fungus extract, the reaction turned from the open yellow to reddish brown. The analysis of samples taken at different times with the UV-Visible Spectrophotometer (UV-Vis) confirms the formation of PE-AgNPs. The Scanning electron microscopy-Energy Dispersive X-Ray Spectrum (SEM-EDX) analysis showed that spherical nanoparticles were formed. X-ray crystallography (XRD), analysis is calculated from Debye-Sherers inequality, in which PE-AgNP synthesized in the study was $18.45 \mathrm{~nm}$ in size. It has been demonstrated by using the minimum Inhibitory Concentration (MIC) method in which AgNPs have strong antimicrobial activity.
\end{abstract}

Keywords: antimicrobial activity, XRD, SEM, TGA-DTA, AgNPs, Pleurotus eryngii

\section{Introduction}

Nanoparticles (NPs) are particles having a size of $100 \mathrm{~nm}$ or less. Because they have a large surface area that allows them to be used in new applications, they tend to react differently from large substances containing the same composition particles (Abou ElNour et al., 2010). The new features that NP has gained make them versatile in many research areas such as biomedical applications, drug exploration, luminescence, cosmetics and renewable energy technologies (Chaudhuri and Paria, 2012; Tran et al., 2013; Rauwel et al., 2015). Therefore many researchers have studied the synthesis of NP using various physical and chemical methods (Remya, et al., 2017). However, it is stated that the synthesis of nanoparticles with green chemistry approaches using biological entities such as plants, fungi, bacteria, algae and actinomycetes provides additional advantages over other methods because it is simple, cost-effective, reliable, and environment-friendly. For this purpose, the use of biological synthesis approaches for many researchers is increasingly important (Kumar and Yadav, 2009).

The fact that microbial infection is a serious problem in the agriculture and healthcare sector has made it mandatory to develop new antimicrobial agents with highly versatile properties such as antimicrobial effect strength, harmonious and low toxicity. In this context, the electrostatic attraction between the positively charged NPs and the negatively charged microbial cells has received worldwide attention due to the 
large surface/volume ratio resulting in improved physicochemical properties of NPs and increased antimicrobial activity (Lakshmeesha et al., 2014; Kavyashree et al., 2015). Antimicrobial properties of NP's, including Antibacterial and antifungal activities, have recently been reported extensively (Mallmann et al., 2015; Salem et al., 2015; Elgorban et al., 2016).

As reported, silver antimicrobial plays a unique role in catalytic and biological systems (Nadagouda et al., 2009). The synthesis of silver nanoparticles, compared to other metals, has become more important as an antimicrobial agent against the everincreasing threats posed by antibiotic resistant microbes (Panaek, et al., 2006; Parashar et al., 2009).

Edible fungi, flavonoids, phenolic acids, tannins and oxidized polyphenols due to numerous reducing biomolecules has attracted great attention in NP synthesis (Philip, 2009; Palacios et al., 2011). In addition, mushroom extract has a high protein content and the carbonyl group of amino acids has the ability to prevent the aggregation of NP's and thus stabilize them in aqueous solution (Al-Batal et al., 2013). Numerous reducing biomolecules, micelles that offer a large surface area for interaction, because of the enzymes they secrete is thought to increase the effect of the functional groups of the nanoparticles and make the mushrooms advantageous compared to other organic sources.

In the literature, it is stated that mushroom extracts such as Volvariella volvacea, Pleurotus sajor Caju, Pleurotus Florida, Ganoderma lucidum, Agaricus bisporus, Inonotus Obliquius were used successfully in AgNP synthesis (Nagajyothi et al., 2014). However, there was no evidence that the Pleurotus eryngii extract was used. In the light of the above information, it is aimed to determine AgNP synthesis, characterization and antimicrobial activity of the obtained PE-AgNP's using Pleurotus eryngii which contains many active ingredients.

\section{Materials and methods}

\section{Macrofungus}

Pleurotus eryngii used in the study was obtained from Hakkari/Turkey in April-May 2018. Diagnostic macroscopic investigations were carried out using field study on ecological structural features and $500 \mathrm{~g}$ samples stored in the MicrobiologyBiochemistry Research Laboratory of Mardin Artuklu University.

\section{Microorganisms}

For testing antimicrobial activity; Escherichia coli ATCC 25922, Staphylococcus aureus ATCC 25923, Streptococcus pyogenes ATCC 19615 Pseudomonas aeruginosa ATCC 27853, standard bacterial strains with Candida albicans ATCC 10231 strains are available in the Microbiology-Biochemistry Research Laboratory of Mardin Artuklu University.

\section{Preparation of mushroom extract}

Pleurotus eryngii extract was used to prepare AgNP synthesis. The mushrooms collected from the field work, after washing with tap water, it was finally washed with distilled water. $200 \mathrm{~g}$ fresh sample, divided into small pieces, was boiled in $90{ }^{\circ} \mathrm{C}$ in distilled water $1000 \mathrm{ml}$. It was then cooled at room temperature and used in the AgNPs synthesis after filtration with Whatman No. 1 Filter paper (Acay et al., 2019). 


\section{Synthesis of PE-AgNPs}

Generally, the color change in the synthesis of AgNPs is determined by timedependent UV-vis spectrophotometry measurements (Pugazhendhi et al., 2018). Therefore $1 \mathrm{mM} \mathrm{AgNO3}$ solution is prepared. The Extract and solution were mixed at the rate of 1:5 and the colour change at room temperature was expected to occur. Reduction of the silver ions was observed to change the white colored solution to dark brown. The resulting dark-colored solution is centrifuged $5 \mathrm{~min}$ at $10000 \mathrm{rpm}$ to remove the upper liquid phase and wash with distilled water until the remaining solid was clear. The obtained AgNPs were left to dry in the oven at $65^{\circ} \mathrm{C}$ for $48 \mathrm{~h}$ and then allowed to dry and stored for characterization.

\section{Characterization of silver nanoparticles}

The characterization of silver nanoparticles was carried out as follows according to the methods described earlier (Baran, 2018). The UV-Vis Spectrophotometer was used which very useful technique for the primary characterization of prepared PE-AgNPs. In the study, the formation of silver nanoparticles was observed with measurements made at one hour intervals using the SHIMADZU UV-3600 Model UV-Vis Spectrophotometer in the reduction of $\mathrm{Ag}+$ ions to Ago form in the solution. The AgilentCary 360 model FTIR device was used for the evaluation of the functional groups involved and responsible for the reduction. The X-ray refractivity pattern of the Obtained nanoparticles was done with the Crystal Dimension analysis RadB-DMAX II computer-controlled X-rays diffraction difractometry. The appearance of the nanoparticles and the silver element composition were analyzed by the EVO 40 LEQ Model device. In order to determine at what temperature the Nanoparticles were deteriorate, the AgNP was used to measure the flow rate of $20 \mathrm{~mL} / \mathrm{min}$ in the $\mathrm{N} 2(\mathrm{~g})$ atmosphere with a heating rate of $10^{\circ} \mathrm{C} / \mathrm{min}$ and the Shimadzu TGA-60 H Model device for TGA and DTA results at $25-900{ }^{\circ} \mathrm{C}$.

\section{Determination of antimicrobial effect}

In the study, Antimicrobial activity Escherichia coli ATCC 25922, Staphylococcus aureus ATCC 25923, Streptococcus pyogenes ATCC 19615 Pseudomonas aeruginosa ATCC 27853, standard bacterial strains and Candida albicans ATCC 10231 strains were determined by using microdilusion method on the Minimum Inhibiting Concentration (MIC) In the study, microplate wells were left to incubate at $37{ }^{\circ} \mathrm{C}$ with the appropriate amounts of Mueller Hinton broth, Mc Farland 0.5 concentration adjusted microorganism solutions and PE-AgNP solution. The lowest concentration in the absence of reproduction after incubation was determined as the MIC value (Wang et al., 2017; Elshikh et al., 2016). Commercial antibiotics were used as control for Gram (+) (vancomycin), Gram (-) (colistin) bacteria and fungus (fluconazole). In addition, the effect of $\mathrm{AgNO}^{3}$ solution was investigated. The study was performed with 3 repetitions and the mean values were determined as MIC value.

\section{Results and discussion}

AgNPs have free electrons that lead to surface plasmon resonance (SPR) absorption band due to the combined vibrations of the electrons of the metal nanoparticles with the light wave in the resonance (Nath et al., 2007). When the Mushroom extract was added 
to an aqueous silver nitrate solvent, the surface of the metal nanoparticles resulted in a colour change from yellow to dark orange (Fig. 1) in 5 days due to stimulation of plasmon vibrations. In the analysis of UV-vis spectroscopy, the formation of silver nanoparticles was observed with samples taken at one hour intervals. As shown in Figure 1, the absorption spectrum values of the samples taken without mixing for one hour at room temperature were measured and gave significant plasmon resonance at a maximum of $461 \mathrm{~nm}$. Ramy and Hashem (2014) in their study using Pleurotus ostreatus extract obtained a maximum value of $450 \mathrm{Nm}$, while Ahmad et al. (2003) reported that the solution prepared using mushroom extract gave a maximum plasmon resonance of $436 \mathrm{Nm}$. Our results are consistent with previous studies (Huang et al., 2007; Verma et al., 2010).
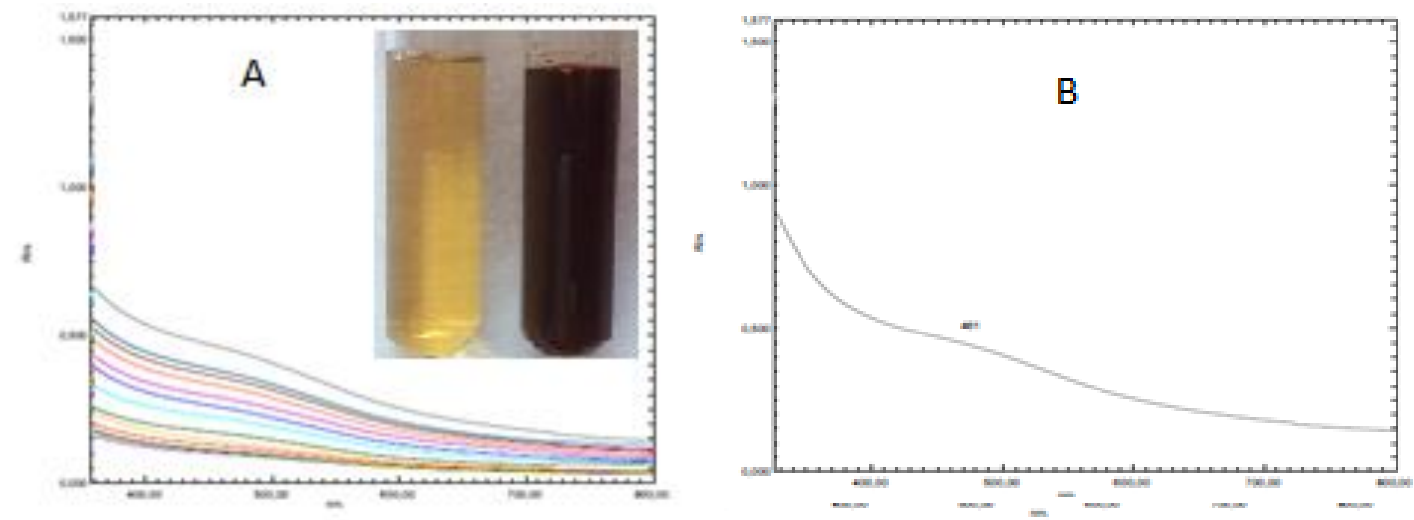

Figure 1. A) Time dependent of PEAgNPs in UV visible spectroscopy. B) Synthesis of PEAgNP at UV spectrophotometry maximum absorbance value

The XRD technique is a non-destructive technique and is used to describe the crystalline phase of nanoparticles. The X-ray diffraction pattern obtained for the PEAgNP sample is shown in Figure 2. The PE-AgNP structure synthesized in the resulting diffraction pattern was obtained from the 111, 200, 220 and 311 characteristic pics $\left(2 \theta=32.41^{\circ}, 46.33^{\circ}, 64.90^{\circ}\right.$ and $77.75^{\circ}$ values $)$. The crystal particle size of the obtained globally structured PE-AgNPs used Debye-Scherrer's inequality; the size of the synthesized nanoparticles was calculated to be $18.45 \mathrm{~nm}$.

From Debye-Scherrer's equation (Baran, 2019):

$$
D=K \lambda /(\beta \cos \theta)
$$

Inequality (Eq. 1): $\mathrm{D}=$ Particle size (nm), $\mathrm{K}=$ Fixed (0.90), $\lambda=$ Wavelength $\mathrm{X}$-ray $\left(1.5406{ }^{\circ} \mathrm{A}\right), \beta=$ half of the highest peak value is specified in radians (FWHM), $\theta=$ fracture angle.

Owait and Ibraheem (2017) reported that mushroom metal-NP's are generally spherical and their size varies between $0.4 \mathrm{~nm}$ and $\geq 300 \mathrm{~nm}$, but most are less than $75 \mathrm{~nm}$. Considering the particle size, especially for biological applications, it is stated that the particle sizes between 30 and $150 \mathrm{~nm}$ are measurable, and a key used in the study of biological properties (Thorek and Tsourkas, 2008). The fact that the crystal grain size of the obtained global structure $P E-A g N P$ is $18.45 \mathrm{~nm}$ suggests a new assessment. 


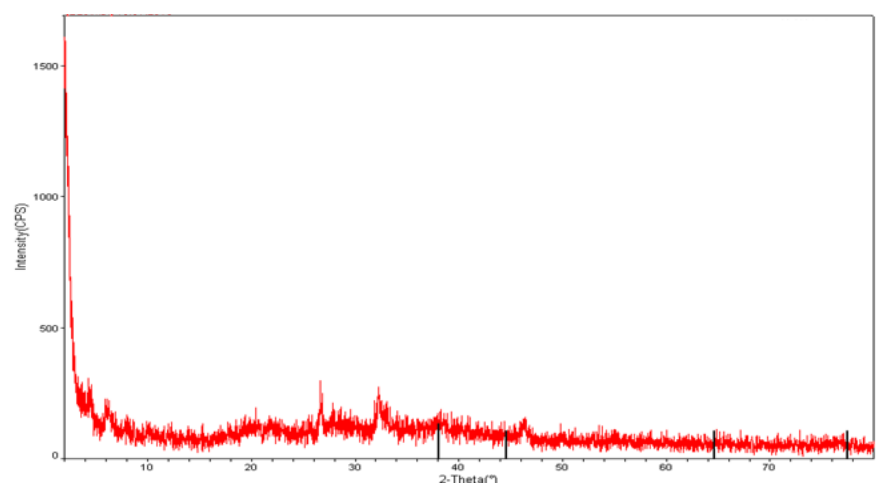

Figure 2. XRD measurements of AgNPs confirming the spherical crystalline structure of PEAgNPs

FT-IR identifies functional groups connected to the surface of metal nanoparticles, since identical absorption patterns are different from those corresponding to free groups, and gives information about the surface chemistry of nanoparticles.

As shown in Figure 3, the results of P. eryngy extract and PE-AgNPs were compared as a result of the FT-IR. It is thought that; the peak at $3529 \mathrm{~cm}^{-1}$ stems from $\mathrm{NH}$; the peak at $3270 \mathrm{~cm}^{-1}$ stems from $\mathrm{OH}$ conjugated to free water, alcohol, and phenol groups; the shift at $1672-1635 \mathrm{~cm}^{-1}$ stems from carbonyl or primary amide band; and the reason for the peak at $2114 \mathrm{~cm}^{-1}$ is $\mathrm{C} \equiv \mathrm{C}$ alkyne or $\mathrm{C}-\mathrm{N}$ group. These functional groups play a role in the reduction (Fig. 3). Mandal et al. (2005) stated that proteins in P. ostreatus fungi could bind to nanoparticles by free amine or cysteine groups in proteins and thus stabilize AgNPs.

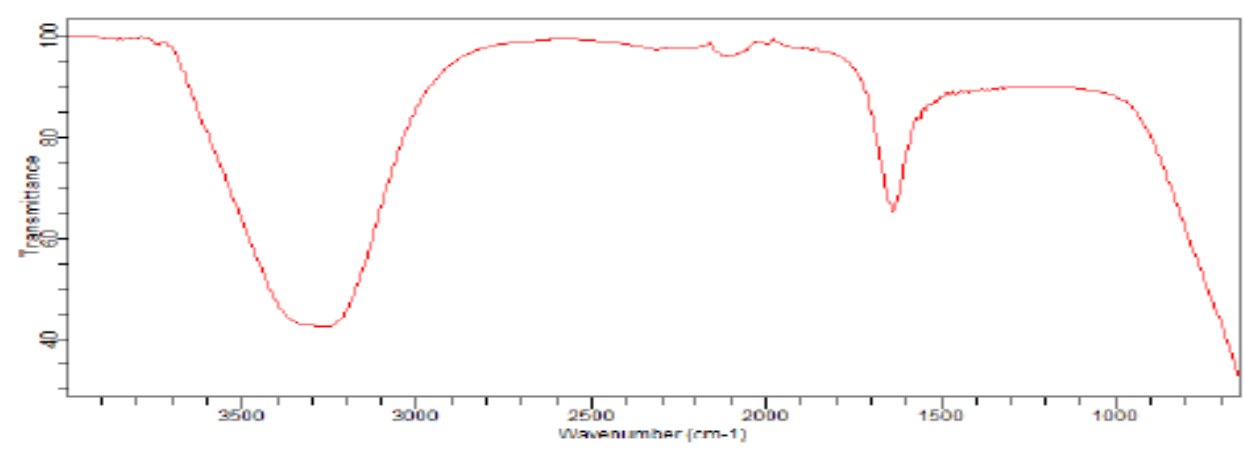

A

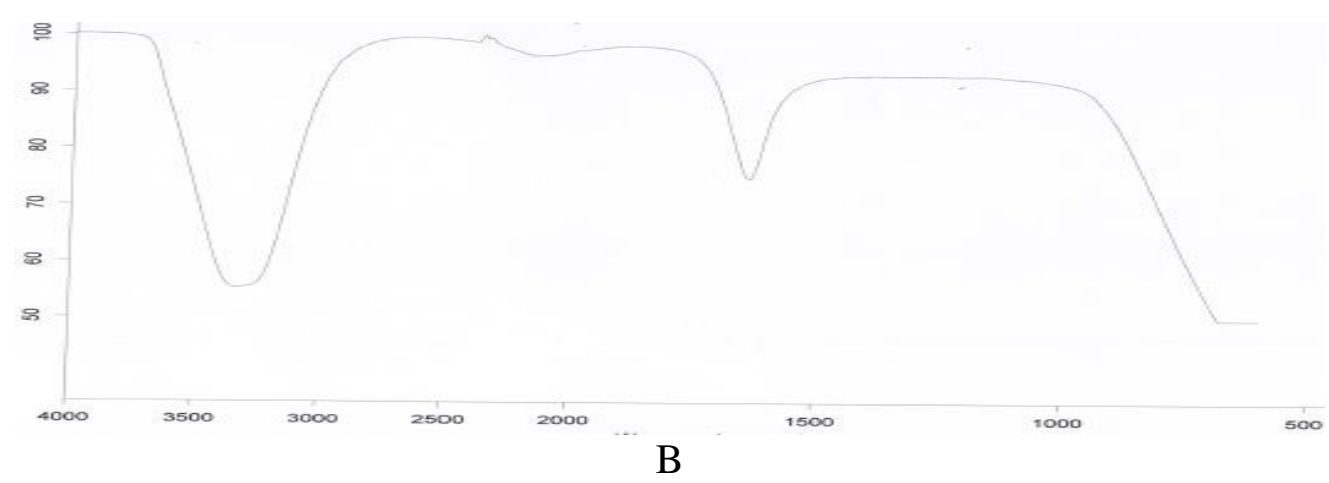

Figure 3. A. FT-IR spectrum of P eryngii extract spectrum. B. FT-IR spectrum of synthesised $P E-A g N P S$ 


$$
-9210-
$$

Scanning Electron Microscope (SEM) is a tool that scans the surface of the sample and records the return of the beam. Since metal nanoparticles are electrically conductive, they are easy to scan with SEM. SEM analyses of spherical PE-AgNP obtained in 18.45 NM size are shown in Figure 4. So far, the researchers have identified a wide range of shapes, such as spherical, diamond, rod-like, and cube, whose diameters are smaller than 1 to $100 \mathrm{~nm}$, as shown in their characterization patterns (Banerjee and Rai, 2017).

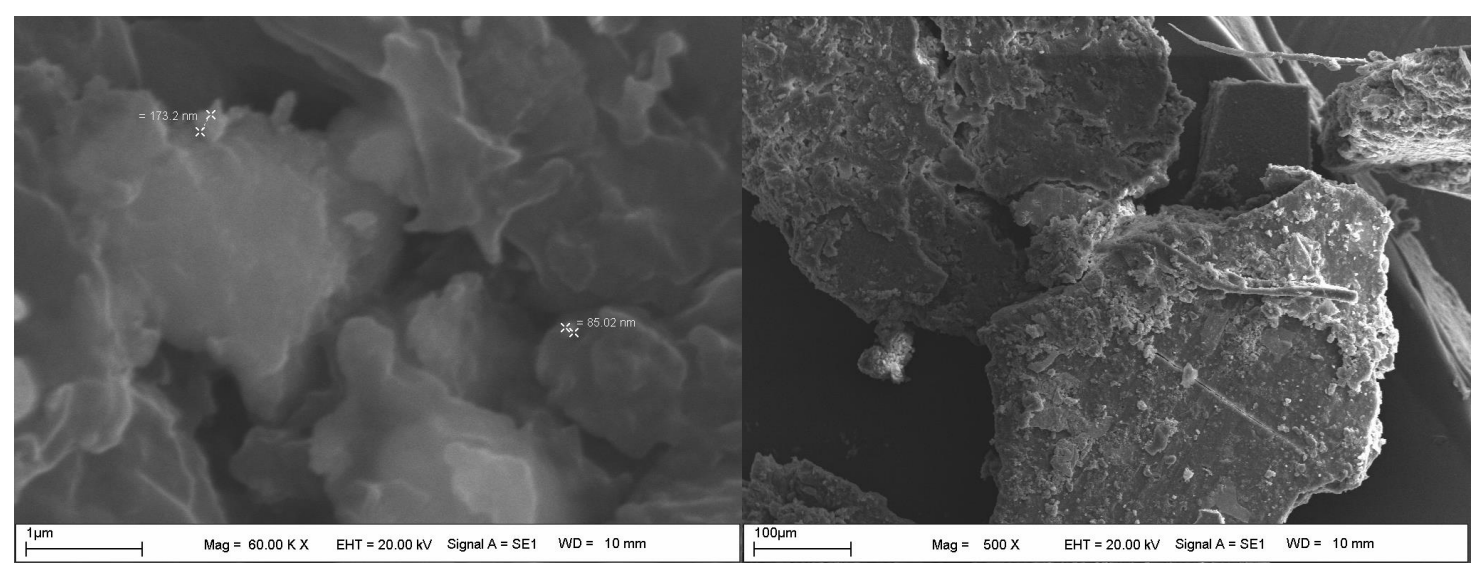

Figure 4. Images of synthesised PE-AgNP of SEM analyses

In addition, it was observed that the particles that were synthesized by EDX analysis were in elemental form (Fig. 5).
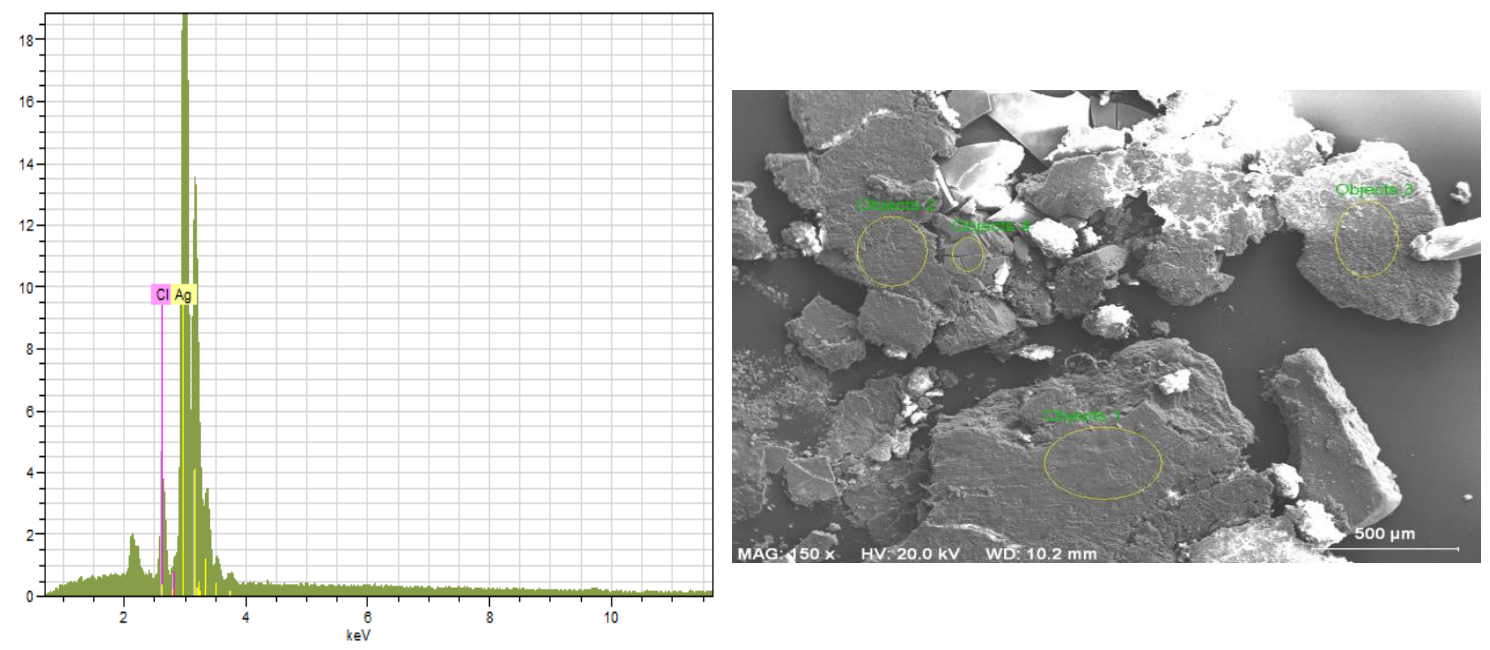

Figure 5. EDX profile of PE-AgNPs showing its elemental composition

Nanoparticles prepared with mushroom extract (PE-AgNPs) between $30-900{ }^{\circ} \mathrm{C}$ TGA and DTA data were analyzed at a flow rate of $20 \mathrm{~mL} \mathrm{~min}^{-1}$ in $\mathrm{N} 2 \mathrm{(g}$ ) atmosphere with a heating rate of $10{ }^{\circ} \mathrm{C} \mathrm{min}-1$. The TGA curve shows a loss of sample mass due to thermal degradation and the DTA curve indicates the maximum temperature of decomposition at each stage of the degradation (Baran, 2019, 2018). It is thought that 
the $3 \%$ mass loss of the synthesized nanoparticule at $11-102{ }^{\circ} \mathrm{C}$ is due to moisture, $2.5 \%$ loss of the $102-179^{\circ} \mathrm{C}$ is due to $\mathrm{H} 2 \mathrm{O}$ formation of $\mathrm{OH}$ groups side by side, $33.5 \%$ loss of the $179-390{ }^{\circ} \mathrm{C}$ is due to phenolicity or ring groups, and the $27 \%$ loss of the 390 $881^{\circ} \mathrm{C}$ is due to the degradation of the substance. In this study, PE-AgNPs synthesized up to $881{ }^{\circ} \mathrm{C}$ were also shown in Figure 6 . Although TGA-DTA analysis of plantderived AgNPs was performed in the literature, no relevant TGA-DTA data on mushroom-based AgNP were found.
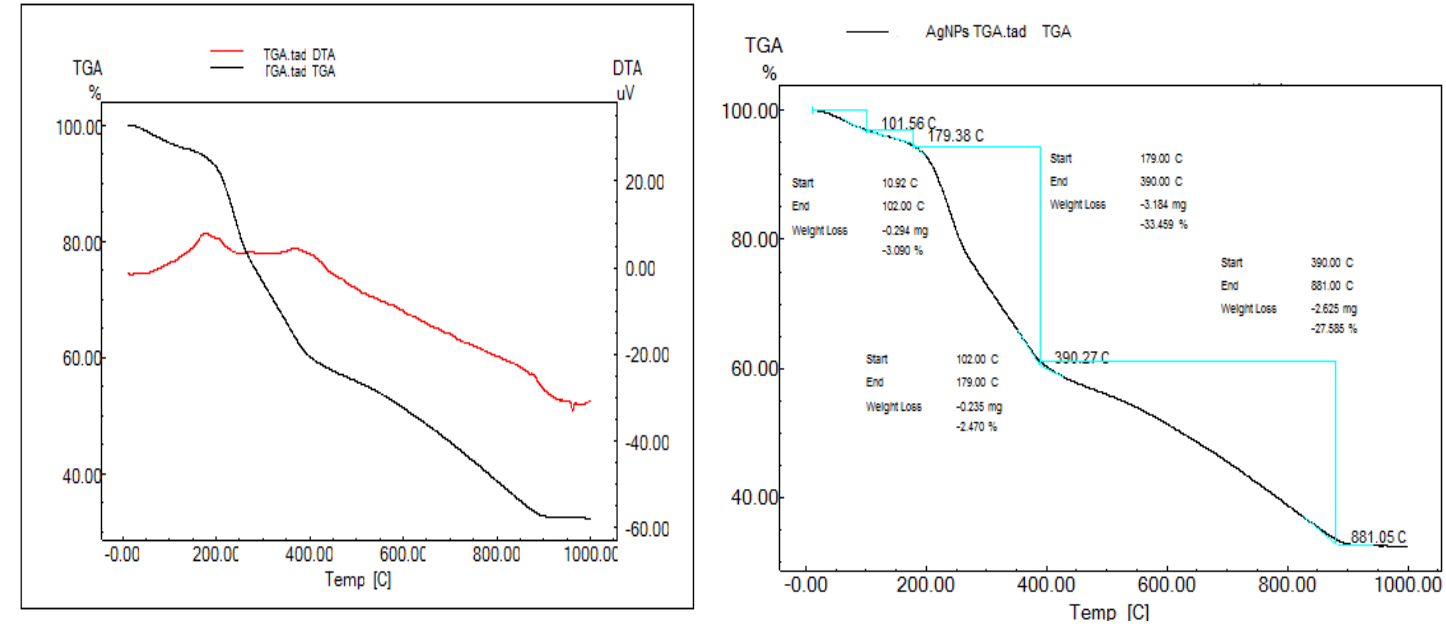

Figure 6. TGA-DTA analysis result of synthesised PE-AgNPs

It is widely known that resistance to antibiotics in microbes is a global problem that worsens at an alarming rate. It has become a major problem in many infectious diseases such as multiple antibiotic resistant bacteria and tuberculosis. Some studies in the past have shown that biologically synthesized metal nanoparticles have more biological activity than physically and chemically synthesized nanoparticles (Antony et al. 2011; Manikprabhu et al., 2013). Gopinath et al. (2015) reported that AgNPs synthesized from Fusarium oxysporum and antibiotics showed antimicrobial activity both individually and in combination against these bacteria the results of the same study confirmed that all resistant bacteria that are normally resistant to antibiotics are sensitive to the presence of AgNPs. In another study, Haq et al. (2015) showed that AgNPs synthesized from five fungal species (Agaricus bisporus, Helvella lacunosa, Ganoderma applanatum, Pleurotus florida and Fomes fomentarius) showed antimicrobial activity against methicillin-resistant S. aureus. However, AgNPs synthesized from Agaricus bisporus have been reported to be more powerful than the other four AgNPs. The antimicrobial activity of PE-AgNPs used in the study against E. coli, S. aureus, $S$. pyogenes and $P$. aeruginosa with standard bacterial strains and $C$. albicans strain is shown in Table 1. MIC values of PE-AgNP and silver nitrate were examined and compared. The study was performed with 3 repetitions and the mean values were determined as MIC value.

The MIC values of $S$. aureus, $S$. pyogenes, E. coli, $P$. aeruginosa and $C$. albicans, respectively, 0.07, 0035, 0.018, 0035 and $0.07 \mathrm{mg} \mathrm{L}^{-1}$ results were obtained (Table 1). Compared with Silver nitrates and antibiotics, AgNP can be used as an alternative to existing antibiotics as a result. 


$$
-9212-
$$

Table 1. MIC values of synthesized PE-AgNPs ( $\left.m g l^{-1}\right)$

\begin{tabular}{c|c|c|c}
\hline Microorganisms & AgNPs & Silver nitrat & Antibiotic \\
\hline $\begin{array}{c}\text { S. aureus } \\
\text { ATCC 25923 } \\
\text { S. pyogenes } \\
\text { ATCC 19615 } \\
\quad \text { E. coli }\end{array}$ & 0.07 & 2.65 & 1 \\
$\begin{array}{c}\text { ATCC25922 } \\
\text { P. aeruginosa } \\
\text { ATCC 27853 } \\
\text { C. albicans }\end{array}$ & 0.035 & 1.32 & 1 \\
ATCC 10231 & 0.018 & 0.66 & 2 \\
\hline
\end{tabular}

\section{Conclusions}

It is clear that $P$. eryngii, a renewable fungus, can be effectively used to synthesize bioactive nanoparticles using cheap substances in an environmentally friendly and nontoxic environment. The synthesis of PE-AgNPs was carried out at room temperature for 5 days by adding the fungus extract to an aqueous silver nitrate solvent. It was observed that PE-AgNPs with a crystal size of $18.45 \mathrm{~nm}$ and a spherical appearance showed a strong antimicrobial activity against human pathogen microorganisms. In this study, we believe that synthesized PE-AgNPs can contribute greatly to the search for antimicrobial agents. At the same time, these biosynthesized AgNPs can be used as effective growth inhibitors in various microorganisms; this makes them applicable to various medical devices, industrial, food, agricultural, biotechnological and environmental applications.

\section{REFERENCES}

[1] Abou El-Nour, M. M., Eftaiha, A., Al-Warthan, A., Ammar, R. A. A. (2010): Synthesis and application of silver nanoparticles. - Arab J Chem 3: 135-140.

[2] Acay, H., Baran, M. F., Eren, A. (2019): Investigating antimicrobial activity of silver nanoparticles produced through green synthesis using leaf extract of common grape (Vitis vinifera). - Applied Ecology and Environmental Research 17(2): 4539-46.

[3] Ahmad, A., Mukherjee, P., Senapati, S., Mandal, D., Khan, M. I., Kumar, R., Sastry, M. (2003): Extracellular biosynthesis of silver nanoparticles using the fungus Fusarium oxysporum. - Colloids Surf B Biointerfaces 28(4): 313-318.

[4] Antony, J. J., Sivalingam, P., Siva, D., Kamalakkannan, S., Anbarasu, K., Sukirtha, R. et al. (2011): Comparative evaluation of antibacterial activity of silver nanoparticles synthesized using Rhizophora apiculata and glucose. - Colloids Surf B Biointerfaces 88(1): 134_40.

[5] Banerjee, K., Rai, V. R. (2017): A review on mycosynthesis, mechanism, and characterization of silver and gold nanoparticles. - Bio NanoSci 8(1): 17-31. https://doi.org/10.1007/s12668-017-0437-8.

[6] Baran, M. F. (2018): Green synthesis of silver nanoparticles (Agnps) using Pistacia terebinthus leaf extract: antimicrobial effect and characterization. - EJONS International Journal on Mathematic, Engineering and Natural Sciences (5)67-75. 
[7] Baran, M. F. (2019): Synthesis, characterization and investigation of antimicrobial activity of silver nanoparticles from Cydonia oblonga leaf. - Applied Ecology and Environmental Research 17(2): 2583-2592.

[8] Chaudhuri, R. G., Paria, S. (2012): A novel method for the templated synthesis of Ag2S hollow nanospheres in aqueous surfactant media. - J Colloid Interf Science 369: 117-122.

[9] El-Batal, A. I., Hashem, A. A., Abdelbaky, N. M. (2013): Gamma radiation mediated green synthesis of gold nanoparticles using fermented soybean-garlic aqueous extract and their antimicrobial activity. - Springer Plus 2: 129-139.

[10] Elgorban, A. M., El-Samawaty, A. M., Yassin, M. A., Sayed, S. R., Adil, S. F., Elhindi, K. M., Bakri, M., Khan, M. (2016): Antifungal silver nanoparticles: synthesis, characterization and biological evaluation. - Agric. Environ. Biotechnol. 30: 56-62.

[11] Elshikh, M., Ahmed, S., Funston, S., Dunlop, P., McGaw, M., Marchant, R., Banat, I. M. (2016): Resazurin-based 96-well plate microdilution method for the determination of minimum inhibitory concentration of biosurfactants, Biotechnol. - Lett. 38: 1015-1019.

[12] Gopinath, P. M., Narchonai, G., Dhanasekaran, D., Ranjani, A., Thajuddin, N. (2015): Mycosynthesis, characterization and antibacterial properties of AgNPs against multidrug resistant (MDR) bacterial pathogens of female infertility cases. - Asian J Pharma Sci 10: $138-45$

[13] Haq, M., Rathod, V., Singh, D., Singh, A. K., Ninganagouda, S., Hiremath, J. (2015): Dried mushroom Agaricus bisporus mediated synthesis of silver nanoparticles from Bandipora District (Jammu and Kashmir) and their efficacy against Methicillin resistant Staphylococcus aureus (MRSA) strains. - Nanosci Nanotechnol Int J 5(1): 1_8.

[14] Huang, J. L., Li, Q. B., Sun, D. H., Lu, Y. H., Su, Y. B., Yang, X., Wang, H. X., Wang, Y. P., Shao, W. Y., He, N., Hong, J. Q., Chen, C. X. (2007): Biosynthesis of silver and gold nanoparticles by novel sundried Cinnamomum camphora leaf. - Nanotechnology 18: $1-11$.

[15] Kavyashree, D., AnandaKumari, R., Nagabhushana, H., Sharma, S. C., Vidya, Y. S., Anantharaju, K. S., Daruka Prasad, B., Prashantha, S. C., Lingaraju, K., Rajanaik, H. (2015): Orange red emitting Eu3 + doped zinc oxide nanophosphor material prepared using Guizotia abyssinica seed extract: structural and pho-toluminescence studies. - J. Lumin. 167: 91-100.

[16] Kumar, V., Yadav, S. K. (2009): Plant-mediated synthesis of silver and gold nanoparticles and their applications. - J. Chem. Technol. Biotechnol. 84(2): 151-157.

[17] Lakshmeesha, T. R., Sateesh, M. K., Daruka, P. B., Sharma, S. C., Kavyashree, D., Chandrashekar, M., Nagabhushana, H. (2014): Reactivity of crystalline ZnO superstructures against fungi and bacterial pathogens: synthesized using Nerium oleander leaf extract. - Cryst. Growth Des. 14: 4068-4079.

[18] Mallmann, E. J. J., Cunha, F. A., Castro, B. N. M. F., Maciel, A. M., Menezes, E. A., Fechine, P. B. A. (2015): Antifungal activity of silver nanoparticles obtained by green synthesis. - Rev. Inst. Med. Trop. Sao Paulo 57: 165-167.

[19] Mandal, S., Phadtre, S., Sastry, M. (2005): Interfacing biology with nanoparticles. - Curr Appl Phys 5: 118-127.

[20] Manikprabhu, D., Lingappa, K. (2013): Microwave assisted rapid and green synthesis of silver nanoparticles using a pigment produced by Streptomyces coelicolor klmp33. Bioinorg Chem Appl. http://dx.doi.org/10.1155/2013/341798.

[21] Nadagouda, M. N., Hoag, G., Collins, J., Varma, R. S. (2009): Green synthesis of Aunanostructures at room temperature using biodegradable plant surfactants. - Cryst. Growth Des. 9: 4979-4983.

[22] Nagajyothi, P. C., Sreekanth, T. V. M., Lee, J. L., Lee, K. D. (2014): Mycosynthesis: Antibacterial, antioxidant and antiproliferative activities of silver nanoparticles synthesized from Inonotus obliquus (Chaga mushroom) extract. - J Photochem Photobiol B Biol 130: 299-304. 
[23] Nath, S. S., Chakdar, D., Gope, G. (2007): Synthesis of CdS and ZnS quantum dots and their applications in electronics. - Nanotrends J. Nanotechnol. Appl. 02(03).

[24] Owaid, M. N., Ibraheem, I. J. (2017): Mycosynthesis of nanoparticles using edible and medicinal mushrooms. - Eur. J. Nanomed. 9(1): 5-23.

[25] Palacios, I., Lozano, M., Moro, C., D’arrigo, M., Rostagno, M., Martínez, J., GarcíaLafuente, A., Guillamón, E., Villares, A. (2011): Antioxidant properties of phenolic compounds occurring in edible mush- rooms. - Food Chem. 128: 674-678.

[26] Panaek, A., Kvitek, L., Prucek, R., Kolar, M., Veerova, R., Pizurova, N., Sharma, V. K., Nevena, T., Zboril, R. (2006): Silver colloid nanoparticles: synthesis, characterization, and their antibacterial activity. - J. Phys. Chem. B 110: 16248.

[27] Parashar, V., Parashar, R., Sharma, B., Pandey, A. C. (2009): Parthenium leaf extract mediated synthesis of silver nanoparticles: a novel approach towards weed utilization. Dig. J. Nanomater Bios. 4: 45-50.

[28] Philip, D. (2009): Biosynthesis of $\mathrm{Au}, \mathrm{Ag}$ and $\mathrm{Au}-\mathrm{Ag}$ nanoparticles using edible mushroom extract. - Spectrochim. Acta Mol. Biomol. Spectrosc. 73: 374-381.

[29] Pugazhendhi, A., Prabakar, D., Jacob, J. M., Karuppusamy, I., Saratale, R. G. (2017): Synthesis and characterization of silver nanoparticles using Gelidium amansii and its antimicrobial property against various pathogenic bacteria. - Microbial Pathogenesis S0882-4010(17)31356-6.

[30] Ramy, S. Y., Hashem, A. S. (2014): Biosynthesis and characterization of silver nanoparticles produced by Pleurotus ostreatus and their anticandidal and anticancer activities. - World J Microbiol Biotechnol 30: 2797-2803.

[31] Rauwel, P., Rauwel, E., Ferdov, S., Singh, M. P. (2015): Silver nanoparticles: synthesis, properties, and applications. - Adv. Mater. Sci. Eng. 624394.

[32] Remya, V. R., Abitha, V. K., Rajput, P. S., Rane, A. V., Dutta, A. (2017): Silver nanoparticles green synthesis: a mini review. - Chem. Int. 3(2) 165-171.

[33] Salem, W., Leitner, D. R., Zingl, F. G., Schratter, G., Prassl, R., Goessler, W., Reidl, J., Schild, S. (2015): Antibacterial activity of silver and zinc nanoparticles against Vibrio cholerae and enterotoxic Escherichia coli. - Int. J. Med. Microbiol. 305: 85-95.

[34] Thorek, D. L., Tsourkas, A. (2008): Size, charge and concentration dependent uptake of iron oxide particles by non-phagocytic cells. - Biomaterials 29(26): 3583-3590.

[35] Tran, Q. H., Nguyen, V. Q., Le, A. T. (2013): Silver nanoparticles: synthesis, properties, toxicology, applications and perspectives. - Adv. Nat. Sci. Nanosci. Nanotechnol. 4: 033001.

[36] Verma, V. C., Kharwar, R. N., Gange, A. C. (2010): Biosynthesis of antimicrobial silver nanoparticles by the endophytic fungus Aspergillus clavatus. - Nanomedicine (Lond) 5 : $33-40$.

[37] Wang, L., Hu, C.., Shao, L. (2017): The antimicrobial activity of nanoparticles: present situation and prospects for the future. - Int J Nanomedicine 12: 1227-1249. 